\title{
Trial assay for safe first-aid protocol for the stinging sea anemone Anemonia viridis (Cnidaria: Anthozoa) and a severe toxic reaction
}

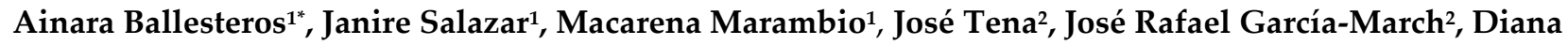 \\ López $^{2}$, Clara Tellez ${ }^{2}$, Carles Trullas ${ }^{3}$, Eric Jourdan ${ }^{3}$, Corinne Granger ${ }^{3}$ and Josep-Maria Gili1 ${ }^{1}$
}

1 ICM-CSIC-Institute of Marine Sciences, Department of Marine Biology and Oceanography, Passeig Marítim de la Barceloneta 37-49, 08003 Barcelona, Spain; jsalazar@icm.csic.es (J.S.); marambio@icm.csic.es (M.M.); gili@icm.csic.es (J.-M.G.)

2 IMEDMAR-UCV-Institute of Environment and Marine Science Research, Universidad Católica de Valencia SVM, C. Explanada del Puerto S/n, 03710 Calp, Alicante, Spain; diana.lopez@ucv.es (D.L.); clara.tellez@ucv.es (C.T.); josetena@ucv.es (J.T.); jr.garcia@ucv.es (J.-R.G.M.)

3 ISDIN, Innovation and Development, C. Provençals 33, 08019 Barcelona, Spain; carles.trullas@isdin.com (C.T.); eric.jourdan@isdin.com (E.J.); corinne.granger@isdin.com (C.G.)

Correspondence: ballesteros@icm.csic.es (A.B.)

\begin{abstract}
Anemonia viridis is an abundant and widely-distributed temperate sea anemone that can form dense congregations of individuals. Despite the potential severity of its sting, few detailed cases have been reported. We report a case of a severe toxic reaction following an $A$. viridis sting in a 35-year-old oceanographer. She developed severe pain, itching, redness and burning sensation, which worsened one week after treatment with antiinflammatories, antihistamines and corticosteroids. Prompted by this event, and due to the insufficient risk prevention, lack of training for marine-environment users and lack of research into sting-specific first-aid protocols, we evaluated the cnidocyst response to five different compounds commonly recommended as rinse solutions in first-aid protocols (seawater, vinegar, ammonia, baking soda and freshwater) by means of the Tentacle Solution Assay. Vinegar and ammonia triggered an immediate and massive cnidocyst discharge after their application and were classified as activator solutions. Baking soda and freshwater were also classified as activator solutions, although with a lower intensity of discharge. Only seawater was classified as a neutral solution and therefore recommended as a rinse solution after $A$. viridis sting, at least until an inhibitory solution is discovered.
\end{abstract}

Keywords: cnidarian venom; cnidocyst discharge; cnidocyte; ocean literacy; risk prevention; seawater; sting; vinegar

Key Contribution: After an A. viridis sting, seawater is recommended as a rinse solution to wash the affected area. Rinse solutions such as vinegar, ammonia, baking soda or freshwater led to cnidocyst discharge and are thus contraindicated for the first-aid protocol.

\section{Introduction}

Cnidarians are recognized as poisonous marine animals. The phylum includes five main classes (Hydrozoa, Scyphozoa, Cubozoa, Anthozoa and Staurozoa), which share a distinctive feature: the presence of cnidocytes [1,2]. The cnidocyte stores a mixture of bioactive toxins in a subcellular-enclosed capsule termed a 
cnidocyst. Cnidocysts are traditionally classified into three categories: nematocyst, spirocyst and ptychocyst $[2,3]$. The nematocyst category is the most varied. Up to thirty types, with different capsule morphologies and tubule patterns, are capable of catching and entangling prey and acting as defence against predators $[2,4,5]$. Differing from nematocysts, the spirocyst and ptychocyst categories are composed of a single type of cnidocyst each [2]. Spirocysts are used to immobilize prey in most anthozoans, and ptychocysts are used by the order Actiniaria and the subclass Ceriantharia for the creation of protective tubes to live in $[4,6]$.

Cutaneous contact between users of marine environments and cnidarians triggers immediate cnidocyst discharge [1,7]. Some types of cnidocytes are able to penetrate human skin, inoculating the venom and causing severe reactions $[7,8]$. The toxicity of cnidarian stings varies across species. In Australia, Chironex fleckeri and Carukia barnesi are responsible for serious health problems and lethal envenomation $[9,10]$. Fortunately, the majority of cnidarians are considered nonlife-threatening species [11] and the severity of their stings depends on various factors (e.g., the composition of the venom, the health conditions of the victim and/or the cnidocyte types) $[8,11,12]$.

In contrast to the high number of fatalities in tropical and subtropical coastal regions $[9,10]$, species that inhabit the Mediterranean Sea commonly cause low to mild skin reactions and annoyances for beach users [13,14], and in isolated cases, systemic symptoms [15-17]. Scyphozoans such as Pelagia noctiluca and Rhizostoma pulmo are common jellyfish in the Mediterranean basin, and their stings are one of the main reasons for seeking assistance from the rescue services $[18,19]$. However, benthic cnidarians, such as sea anemones, are also responsible for severe skin reactions in the Mediterranean basin [17,20,21].

The snakelocks sea anemone Anemonia viridis is a temperate anthozoan distributed throughout the Mediterranean Sea and in the northern area of the Atlantic Ocean, from the North Sea to the Azores [22]. A. viridis clonemates can cover wide areas of the seafloor, playing an important role as a dominant predator in benthic communities [23]. The species' complexity has been largely studied, but it is important to highlight that due to the presence of different morphotypes and continuous advances in research, there is no consensus on its taxonomy [24]-in this article it is referred to as $A$. viridis because it is the most recognized and accepted nomenclature [24]. Five different morphotypes of A. viridis and four cryptic species have been described to date [25]. The cnidome, which includes the total complement of cnidocytes within a cnidarian specimen [5], comprises four cnidocyte types in adult individuals collected in the North Adriatic Sea; three nematocysts (holotrichous isorhiza, p-mastigophore and a possible microbasic bmastigophore) and one spirocyst [26]. Envenomation from sea anemones usually involves mild signs and symptoms of erythema, irregular and painful plaques and papules $[17,20,27,28]$; rarely, cases of $A$. viridis stings have been reported $[17,20]$.

The diversity of cnidarian species and the lack of studies providing scientific evidence on the effectiveness of first-aid protocols [29] increase the risk of inadequate treatment of users of marine environments. First-aid protocols are focused on two clear actions [30]: (1) rinsing the affected area with a safe rinse solution to remove remaining tissues (e.g., pieces of tentacles) and/or residual cnidocytes after a sting and (2) reducing pain or symptoms. Despite the importance, the scientific community remains in disagreement on which are the best rinse solutions or treatments to provide appropriate care, which is confusing for medical professionals, lifeguards and the general public [7,12,29,31-33]. Seawater, vinegar or acetic acid, freshwater and/or baking soda are commonly used as topical rinsing 
solutions [7], despite the fact that they are not always the best option depending on the stinging species.

In recent years, researchers have highlighted the importance of establishing species-specific first-aid protocols to avoid extrapolating results that may lead to bad care practices due to differences in cnidocyst response between classes of the Cnidaria phylum $[29,33]$. Although the use of vinegar has traditionally been recommended [32,34], its unequal effectiveness between species is increasingly supported by scientific evidence $[29,33,35]$. While vinegar is an inhibitor of cnidocyst discharge in cubozoans [29,34], its application causes immediate discharge in scyphozoans and hydrozoans $[29,33,36]$. Until the present study, neither its effectiveness, nor that of other compounds commonly used as rinse solutions (e.g., ammonia, freshwater, baking soda), had been tested for A. viridis, leaving the first-aid guidelines for Mediterranean sea anemone stings without any scientific basis [37-39].

In this article we present (1) a case study of a severe toxic reaction to A. viridis in a young woman working as an oceanographer, and also, for the first time, (2) an evaluation of the response of $A$. viridis cnidocysts to the presence of different topical rinse solutions, including vinegar, to establish guidelines for safe first-aid protocols for its sting.

\section{Results}

2.1. A severe toxic reaction following Anemonia viridis sting On 5th March 2021, a group of oceanographers were working in an area of approximately $1 \mathrm{~m}$ depth in Alfacs Bay, on the southern coast of Catalonia (Spain) (Figure 1A, 1B). The daily tasks of the group included the handling of bivalve mollusc individuals of the species Pinna nobilis (Figure 2A), whose organisms are often characterized by high and diverse levels of epibionts, including sea anemones (Figure 2B).

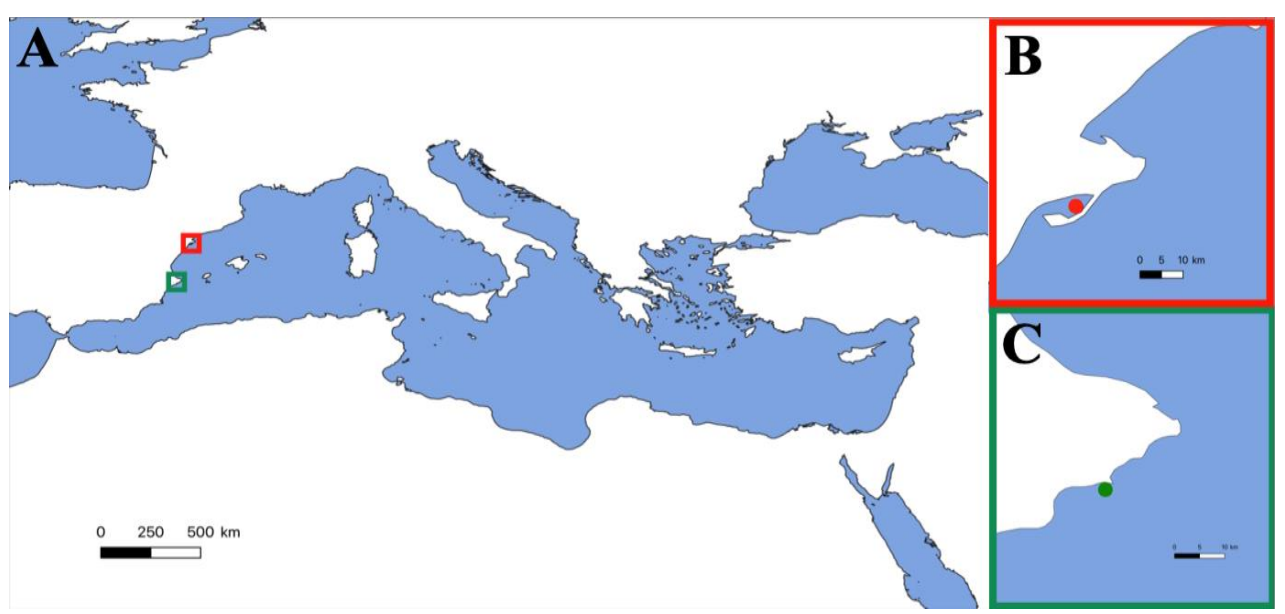

Figure 1. (A) Mediterranean Sea. (B) Alfacs Bay (north-western Mediterranean). Location of the interaction between the patient and the sea anemone (red dot). (C) Sample collection of Anemonia viridis for first-aid protocol experiments (green dot). 


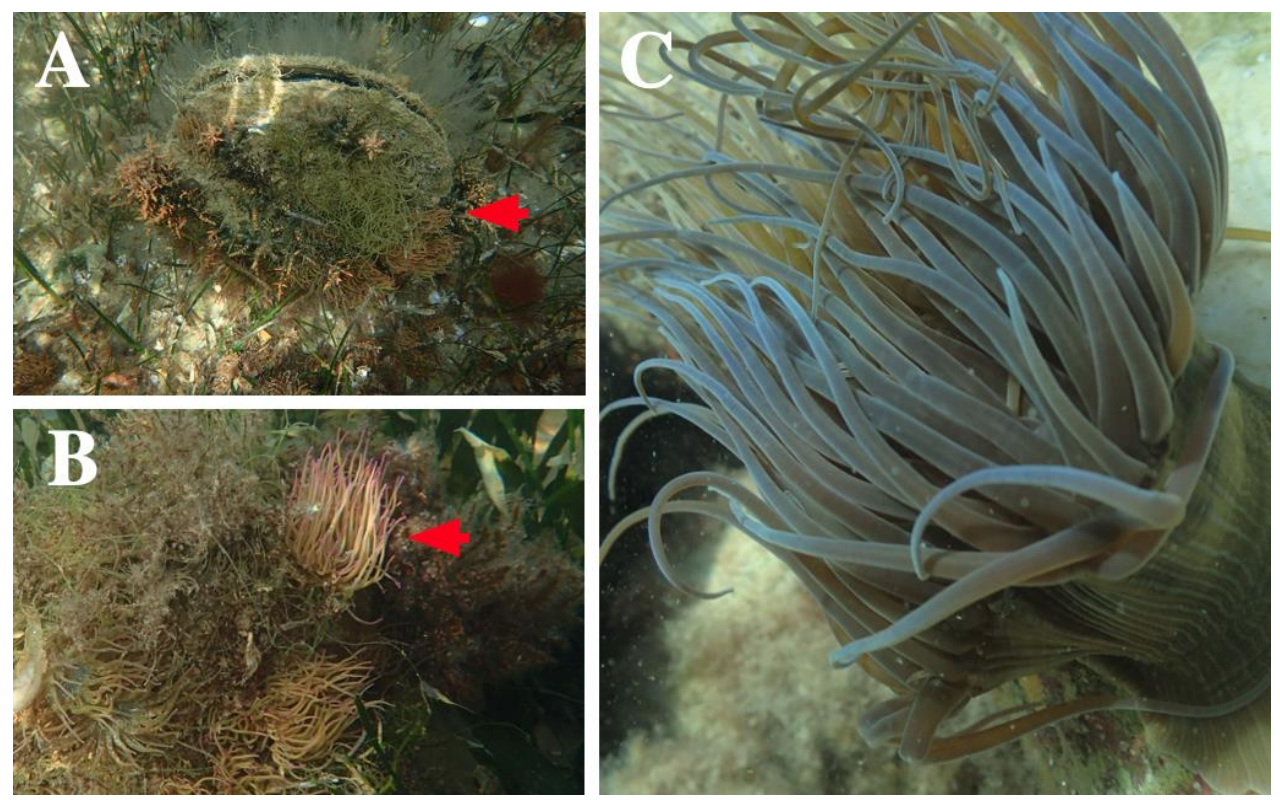

Figure 2. (A, B) Individuals of the species Pinna nobilis covered with high densities of sea anemone (red arrows) in Alfacs Bay (Spain). (C) Anemonia viridis in low bathymetric area sampling in Calp (Spain).

The group was insufficiently protected, wearing only short-sleeved T-shirts and long waterproof pants. After approximately $30 \mathrm{~min}$, one of the oceanographers started to experience itching and redness on her forearms which increased progressively (Figure 3A). She washed the affected area with seawater, perceiving a little relief with this. After the group finished their daily tasks, the affected area was exposed to sunshine for 3.5 hours on the way back from sampling.

Once back at the research centre, severe remitting pain, itching and burning sensation led her to attend the health centre. The prescribed treatment included parenteral antihistamines and anti-inflammatories, oral antihistamines and oral and topical corticosteroids, and she returned home. The next day, 10 min after the use of the topical corticosteroid cream, she had an allergic reaction-she reported an episode of her face flushing red and feeling hot. She went back to the health centre and the doctor stopped the corticosteroid cream and diagnosed an allergic reaction to an ingredient in the cream, since the patient reported having been treated with corticosteroids previously without any reaction. The new treatment consisted of a second dose of parenteral antihistamines and anti-inflammatories, oral antihistamines and only oral corticosteroids, with a gradually decreasing dose over one week. The young woman experienced some alleviation over the first few days but soon worsened, with an increase in pain, itch, redness and swelling in the stung area (Figure 3B). She received a third dose of antihistamines and antiinflammatories parenterally at the health centre and oral antihistamines and highdose oral corticosteroids for one month at home. Finally, she improved slowly and scabs began to form on the affected area. Six months after the exposure to the toxic venom of $A$. viridis (September 2021), the area had mild hyperpigmentation. 

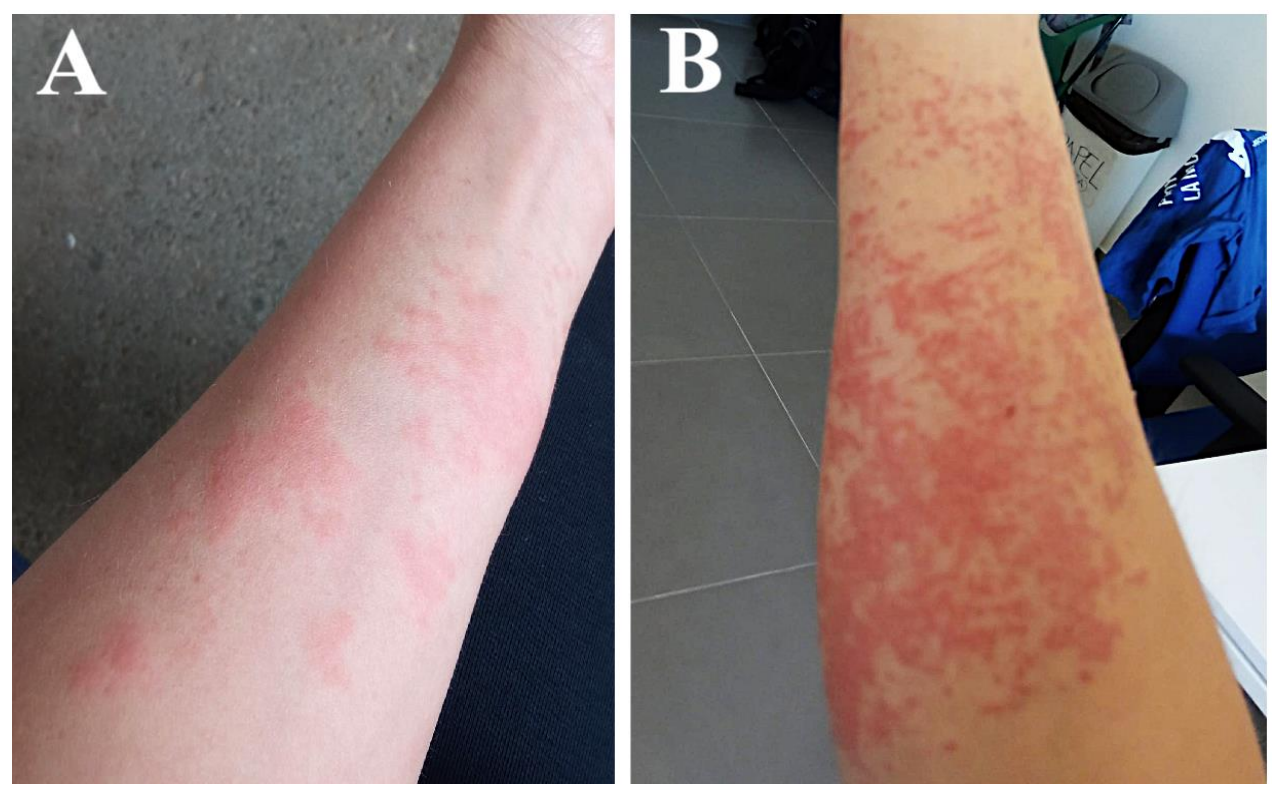

Figure 3. (A) Anemonia viridis sting sustained by the patient during field work. (B) Worsening of the affected area.

2.2. First-aid protocols: Response of Anemonia viridis cnidocysts to topical rinse solutions

Five test solutions widely used in cnidarian first-aid protocols (seawater, vinegar, ammonia, $10 \%$ baking soda mixed in seawater, and freshwater) were evaluated (Table 1).

Seawater did not stimulate cnidocyst discharge in the tentacles of $A$. viridis (Figure 4B), so it was classified as a neutral rinse solution (Table 1). In contrast, application of rinse solutions of vinegar and ammonia produced significant cnidocyst discharge (Figure 4C, D). The application of a solution of $10 \%$ baking soda mixed in seawater triggered a medium level of discharge (Figure E) compared to the immediate and massive discharge in vinegar and ammonia (Figure 4C, D). Freshwater produced a low level of cnidocyst discharge, and isolated undischarged cnidocytes were commonly observed (Figure 4F). Therefore, all the compounds except seawater were classified as activator rinse solutions, although with different degrees of discharge intensity (Table 1).

Table 1. Anemonia viridis cnidocyst response after the application of different rinse solutions.

\begin{tabular}{lccc}
\hline & Anemonia viridis & \\
\hline Rinse solutions & $\mathbf{n}$ & Discharge $^{1}$ & Effect $^{2}$ \\
\hline Seawater & 20 & 0 & Neutral $^{-}$ \\
Vinegar & 20 & +++ & Activator \\
Ammonia & 20 & +++ & Activator \\
$10 \%$ Baking soda mixed in seawater & 20 & ++ & Activator \\
Freshwater & 20 & + & Activator \\
\hline
\end{tabular}

Method: Tentacle Solution Assay. ${ }^{1}$ Cnidocyst discharge categories: $0=$ no discharge of cnidocysts; + = low discharge of cnidocysts; ++ = medium discharge of cnidocysts; +++ = high discharge of cnidocysts. ${ }^{2}$ Rinse solution categories: neutral solution $=$ cnidocysts are not 
activated after the application of the solution; activator solution = cnidocysts are activated after the application of the solution; $n$ indicates the number of replicates.
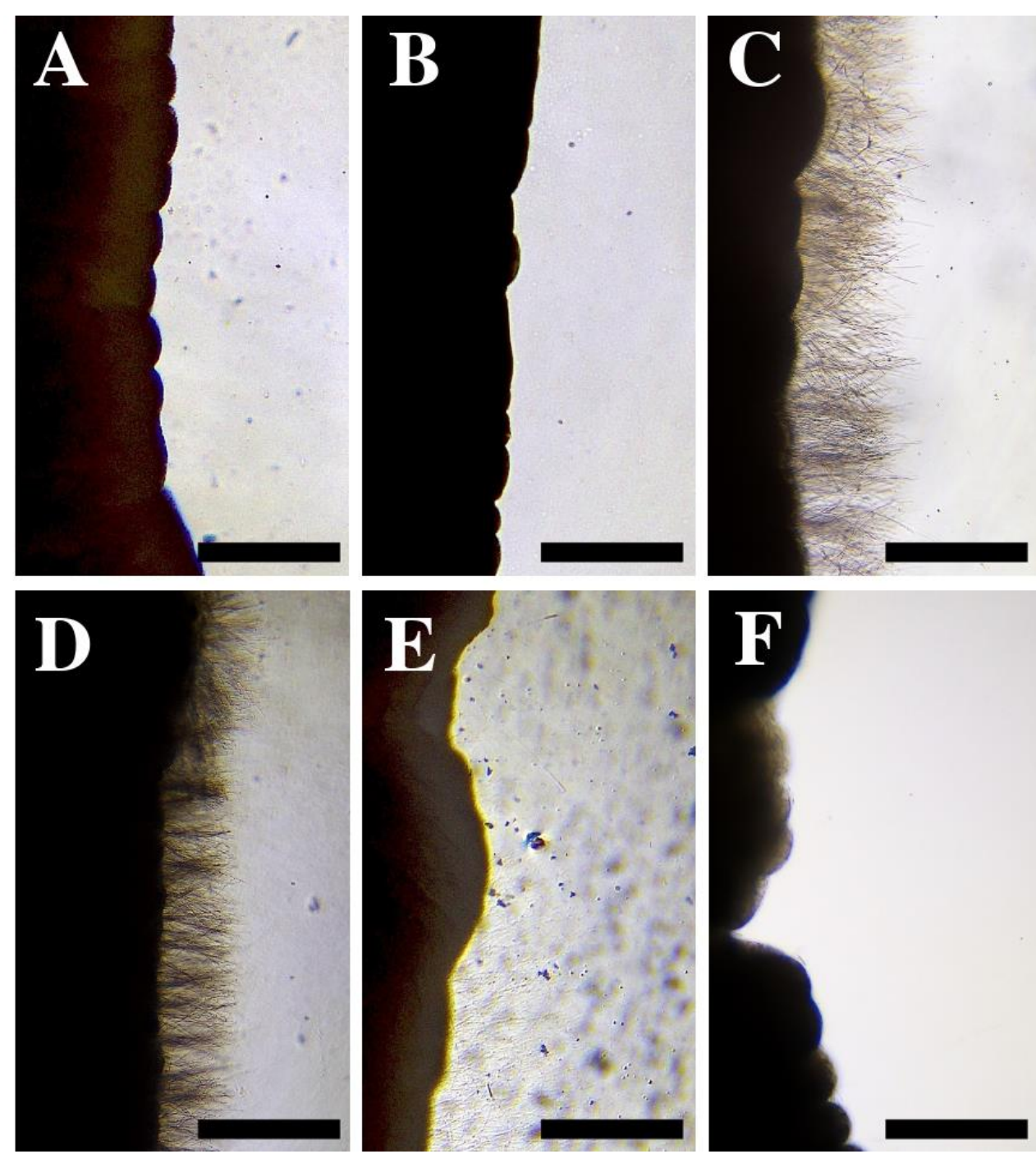

Figure 4. (A) Tentacle pieces of Anemonia viridis without any treatment. (B-F) Cnidocyst responses after the application of: (B) seawater, (C) vinegar, (D) ammonia, (E) $10 \%$ baking soda mixed in seawater and (F) freshwater. Note the different response between a neutral solution (B) and an activator solution (C-F). Scale bars: $0.5 \mathrm{~mm}$.

\section{Discussion}

In the Mediterranean Sea, cnidarian envenomation commonly causes local cutaneous reactions after accidental skin contact; sting episodes with systemic manifestations, including anaphylactic reactions, may also occur [15-17]. Although the Mediterranean sea anemone sting causes mild symptoms that do not require hospitalization, severe, isolated cases in children have triggered symptoms such as fever and loss of appetite or mobility [17]. In the present case report, the young oceanographer experienced a severe reaction to an $A$. viridis sting which worsened in the consecutive weeks. Cutaneous lesions after cnidarian envenomation can be recurrent, delayed, persistent and occur in different body areas distant from the primary sting $[15,37,40-42]$

Low levels of ocean literacy have been widely reported in different countries and different sectors of society [43-45], particularly regarding knowledge related to cnidarians [46]. Unlike other cases of envenomation in bathers $[15,17,21]$, the 
accident occurred during working hours and a lack of awareness on risk prevention training was identified. In the case reported here, the patient was able to identify the species due to her experience with marine organisms, but such a background is uncommon [17]. Specific training about venomous marine biodiversity should be included in risk prevention training. Educational initiatives (e.g., Observadores del Mar [47]) and useful identification guides (Appendix A), as well as the use of mobile applications that report the presence or absence of jellyfish in real-time (e.g., MedJelly app [48,49]) are successful tools that provide the best scientific knowledge necessary for identification and awareness of the presence of cnidarians in the work area. The sting reported in the present study could have been avoided by the use of physical barriers that prevent cnidocyte penetration [50]. Wearing protective clothing should have been mandatory in an area with a high presence of sea anemones such as Alfacs Bay (Figure 2A, B). Moreover, the worker should probably have avoided sun exposure on her way back from work, something which likely worsened the sting, since prolonged sun exposure is contraindicated in cases of cnidarian envenomation [51]. The amount of sun exposure is an essential question in the history to obtain detailed information about the cnidarian sting [52].

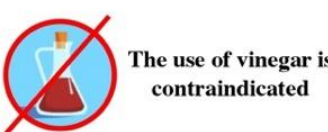

1

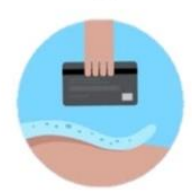

Remove pieces of tentacles with a rigid element

\section{FIRST AID PROTOCOL Anemonia viridis}

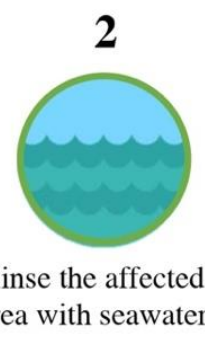

3

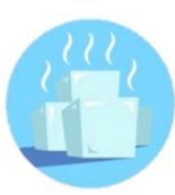

Apply ice packs during 15 mins $(3+2)$

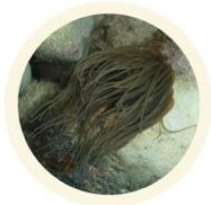

4

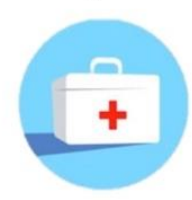

If the pain persists, go to the nearest health center

Figure 5. First-aid protocol for stings by the sea anemone Anemonia viridis.

Updated first-aid protocols based on scientific advances are essential tools to prevent harm. In recent decades there has been a growth in scientific reports warning of the ineffectiveness of vinegar as a rinse solution for the treatment of cnidarian stings $[29,33,35,36,53]$, with the exception of cubozoans where its use is effective $[29,33,34]$. Immediate $A$. viridis cnidocyst discharge was observed after vinegar application (Figure 4C), indicating it should not be used as a rinse solution following a snakelocks sea anemone sting. This is the first time that the effectiveness of vinegar for A. viridis has been evaluated, yet some guidelines in reports from the medical community have recommended the use of vinegar for cleaning the affected area [37-39]. Herein, we have demonstrated that vinegar application is strictly contraindicated for $A$. viridis stings due to its potential as an activating solution (Table 1), producing a worsening of the affected area. This is also the case in other species of scyphozoans and hydrozoans $[29,33,36,53]$, including the most important Mediterranean jellyfish $P$. noctiluca [29], which is responsible for the majority of jellyfish sting cases seeking assistance from lifeguards in certain Mediterranean beaches [18].

As with vinegar, the use of ammonia has also been suggested as a solution for washing the affected area following a Mediterranean sea anemone sting, without any scientific evidence [37]. After the immediate and massive cnidocyst discharge 
observed in this study (Figure 4D), we report the detrimental effect of its use. In the case of baking soda, some studies have shown negligible discharge in some cubozoans, scyphozoans and hydrozoans [31,53] with the exception of increased discharge in the scyphozoan $P$. noctiluca [54]. According to our results, the application of baking soda induced cnidocyst discharge in $A$. viridis (Figure $4 \mathrm{E}$ ), although with less intensity than the other compounds; nonetheless, its use should be contraindicated.

Rinsing with freshwater is not advised in cnidarian first-aid protocols $[7,14,55]$ because the osmotic change can promote the activation of cnidocysts [55]. In the present study we observed a low level of discharge (Figure 4F) and the detachment of some intact cnidocytes after freshwater application. Residual cnidocytes could roll off the skin and be activated by mechanical effects [32,34]. For this reason, the use of freshwater is not recommended for $A$. viridis stings.

Use of seawater in first-aid protocols is questionable, since although it is considered a neutral and non-inhibiting solution, it could still cause discharge by mechanical effects $[31,32,34]$. It is considered neutral for cnidarian species, as well as for $A$. viridis as reported here (Table 1 and Figure $4 B$ ), so its use is recommended in numerous studies [29,33,35], especially when the victim is not able to recognize the species (Appendix A). Rinsing with seawater may relieve pain after stinging, as happened in the case described here, where the patient reported a little relief. Although the best option is to wash the sting site with an inhibitory solution [29], none have been identified for $A$. viridis; therefore, despite only being neutral (Table 1), we recommend seawater use until new inhibitory substances are found, as in the case of other Mediterranean cnidarians (Figure 5 and Appendix A) [29].

After safely removing tissues and/or residual cnidocytes using the rinse solution, the next step in first-aid protocols is to attenuate local pain and inflammation while trying to prevent tissue damage, inactivate toxins from the venom and prevent venom diffusion [12]. Again, the scientific community remains in disagreement on whether to use heat (e.g., hot-water immersion, hot packs or hot showers) or cold (e.g., ice packs or cold-water immersion) for this step $[7,56]$. Although the mechanism of action is still unclear, a recent systematic review recommended the use of $45^{\circ} \mathrm{C}$ water immersion of the stung area for $20 \mathrm{~min}$ as the best treatment, supported by evidence of the thermolability of marine venoms, including cnidarians, and the interference of the heat in pain transmission, thus relieving pain [56]. The application of cold packs is reported as having a potent analgesic effect [57]. In the case of non-life-threatening species stings involving mild to moderate pain, such as $A$. viridis, the application of cold-water or cold packs is useful and easy to perform for lifeguards or even beach users. For a better understanding of the effects of hot or cold treatments, future clinical experiments are required in Mediterranean cnidarians to help clarify their implications and update the current guidelines where necessary (Appendix A).

\section{Conclusions}

Although most sea anemone stings do not pose a risk to human health, knowing the correct guidelines in the first-aid protocols helps prevent the sting from worsening. Our research reveals the ineffectiveness-and indeed contraindication - of vinegar as a rinse solution, as well as that of ammonia, baking soda and freshwater, for $A$. viridis sting. In addition, we strongly recommend the use of physical barriers such as stinger suits, wet-suits or dry-suits to prevent the injection of cnidocytes for users of coastal environments, including sea workers. Avoidance of sun exposure is advised in severe stings.

The appropriate first-aid protocol after $A$. viridis sting includes the following (Figure 5): (1) remove pieces of tentacles or other tissues with a rigid element such as a credit card or tweezers. Never rub. (2) Rinse the affected area with seawater 
(never vinegar, ammonia, baking soda or freshwater). (3) Apply ice packs for 15 min in intervals of $5 \mathrm{~min}$. ( $3 \mathrm{~min}$ of application and $2 \mathrm{~min}$ of rest). (4) If pain persists, go to the nearest health centre.

Efforts to improve ocean literacy are essential and urgent in those who provide first-aid in order to revert dangerous trends that threaten users exposed to venomous organisms. First, an agreed framework is urgently needed to adopt and implement first-aid protocols for cnidarian species, as well as further development of discharge-inhibiting substances that can act as an effective rinsing solution to safely remove tissues and/or residual cnidocytes after a sting. More efforts should be made to better train lifeguards, health professionals and users of coastal environments and provide them with specific and updated materials (Appendix A).

\section{Materials and Methods}

5.1 Interview with the patient

The questionnaire included the following information modified from Burnett (2001) [52]:

Details of the sting:

1. Date, time, location

2. Cnidarian species that caused the sting

3. Patient activity at the time of the sting

4. Water conditions and amount of sun exposure

5. Clothing or sun cream protection

6. Part of body stung

Symptoms:

1. Local symptoms: e.g., pain, redness, papules, swelling

2. Systemic symptoms: e.g., fever, muscle spasms, nausea

Past medical history:

1. Past cnidarian sting

2. Significant medical diseases

3. Drugs taken at the time of the sting

4. Allergy history: e.g., asthma, hay fever

5. Any current medications

First-aid protocols:

1. Did you notice any remains of cnidarian tissue attached after the sting? How did you remove them?

2. First-aid protocol for rinsing the sting area: e.g., use of seawater, vinegar

3. First-aid protocol for relieving pain: e.g., hot or cold application

4. Did you know the proper first-aid protocol for cnidarian stings? ("cnidarian" includes animals such as jellyfish, sea anemone and coral)

5. Had you previously received any information on how to act in case of a cnidarian sting during occupational risk training?

6. Did you need medical assistance? e.g., time of arrival at health centre, number of visits, treatment, outcome

Other information:

1. Any other information that you would like to provide?

The patient received and signed a consent form before the interview.

5.2 First-aid protocol experiments 


\subsubsection{Sea anemone collection}

Anemonia viridis specimens were collected during scuba dive sampling in September 2021 along the Calp coast (Alicante, Spain) (Figure 1C, 2C). To ensure the integrity of the tentacles, whole individuals were collected using spatulas and transferred to recipients full of seawater, avoiding air bubbles inside in order to maintain the organisms in the best conditions. Then, the specimens were transported to the Institute of Environmental Research and Marine Science (IMEDMAR-UCV) laboratories for maintenance, where they were kept in aquarium tanks without feeding until their use (less than 48h).

\subsubsection{Tentacle Solution Assay [34]}

The evaluation of cnidocyst discharge was tested in five rinse solutions: seawater, vinegar (Vivó, 6\% acetic acid), ammonia (Hacendado), 10\% baking soda (Hacendado) in seawater, and freshwater (Table 1).

Tentacle pieces of approximately $3 \mathrm{~cm}$ long from 8 individuals of A. viridis were transferred to slides $(76 \times 26 \mathrm{~cm})$. The samples were observed under the light microscope to ensure their integrity (Figure 4A). $15 \mu \mathrm{l}$ of each solution were applied to the tentacle to determine the effect on discharge during a period of 30 seconds. As defined by Ballesteros et al. (2021) [29], the study area was the rim of the tentacle.

The cnidocyst response was classified qualitatively into four categories [33]:

1. 0 : no discharge observed;

2. +: low discharge of cnidocysts;

3. ++: medium discharge of cnidocysts;

4. +++: high discharge of cnidocysts.

The effect of the rinse solution was classified into one of the following two categories:

1. Activator effect solution: cnidocysts were activated after the application of the solution;

2. Neutral effect solution: cnidocysts were not activated after the application of the solution.

Author Contributions: A.B. and J.S. conceived the study, conducted the interview with the patient, performed the experiments and analyzed the data. A.B. designed the experiment, wrote and edited the original manuscript. J.S. and M.M. participated in the writing of the manuscript. J.S., C.T. and J.T. sampled and collected the A. viridis individuals for this study. D.L., C.T., J.T. and J.-R.G.M. provided all the facilities to make the study possible. All authors revised the manuscript and contributed to its improvement. All authors have read and agreed to the published version of the manuscript.

Funding: This research was funded by ISDIN (Barcelona, Spain).

Institutional Review Board Statement: Not applicable.

Informed Consent Statement: Written informed consent has been obtained from the patient to publish this article.

Data Availability Statement: Data sharing not applicable. No new data were created or analyzed in this study.

Acknowledgments: The authors would like to thank all the personnel from IMEDMAR-UCV who assisted with the experiments.

Conflicts of Interest: The authors declare no conflict of interest.

Appendix A: Guía de identificación de medusas y otros organismos gelatinosos. 


\section{References}

1. D'Ambra, I.; Lauritano, C. A review of toxins from cnidaria. Marine Drugs 2020, 18, 507, doi:10.3390/md18100507.

2. Mariscal, R. Nematocysts. In Coelenterate Biology: Reviews and new perspectives; Muscatine, L., Lenhoff, H.M., Eds.; Academic Press: New York, 1974; pp. 129-166.

3. Watson, G.M.; Wood, R.L. Colloquium on Terminology. The Biology of Nematocysts 1988, 21-23, doi:10.1016/B9780-12-345320-4.50006-7.

4. Östman, C. A guideline to nematocyst nomenclature and classification, and some notes on the systematic value of nematocysts. Scientia Marina 2000, 64, 31-46, doi:10.3989/SCIMAR.2000.64S131.

5. Ballesteros, A.; Östman, C.; Santín, A.; Marambio, M.; Narda, M.; Gili, J.-M. Cnidome and morphological features of Pelagia noctiluca (Cnidaria: Scyphozoa) throughout the different life cycle stages. Frontiers in Marine Science 2021, 8, 1059, doi:10.3389/fmars.2021.714503.

6. Özbek, S.; Balasubramanian, P.G.; Holstein, T.W. Cnidocyst structure and the biomechanics of discharge. Toxicon 2009, 54, 1038-1045, doi:10.1016/j.toxicon.2009.03.006.

7. Killi, N.; Mariottini, G.L. Cnidarian jellyfish: ecological aspects, nematocyst isolation, and treatment methods of sting. In Results and Problems in Cell Differentiation; Springer Verlag, 2018; Vol. 65, pp. 477-513.

8. Kitatani, R.; Yamada, M.; Kamio, M.; Nagai, H. Length is associated with pain: jellyfish with painful sting have longer nematocyst tubules than harmless jellyfish. PLOS ONE 2015, 10, e0135015, doi:10.1371/journal.pone.0135015.

9. Currie, B.J.; Jacups, S.P. Prospective study of Chironex fleckeri and other box jellyfish stings in the "Top End" of Australia's Northern territory. Medical Journal of Australia 2005, 183, 631-636, doi:10.5694/j.13265377.2005.tb00062.x.

10. Little, M.; Pereira, P.; Mulcahy, R.; Cullen, P.; Carrette, T.; Seymour, J. Severe cardiac failure associated with presumed jellyfish sting. Irukandji Syndrome? Anaesthesia and Intensive Care 2003, 31, 642-647, doi:10.1177/0310057x0303100605.

11. Jouiaei, M.; Yanagihara, A.; Madio, B.; Nevalainen, T.; Alewood, P.; Fry, B. Ancient venom systems: a review on cnidaria toxins. Toxins 2015, 7, 2251-2271, doi:10.3390/toxins7062251.

12. Remigante, A.; Costa, R.; Morabito, R.; la Spada, G.; Marino, A.; Dossena, S. Impact of scyphozoan venoms on human health and current first aid options for stings. Toxins 2018, 10, 133. doi: 10.3390/toxins10040133

13. Mariottini, G.L.; Pane, L. Mediterranean jellyfish venoms: a review on scyphomedusae. Marine Drugs 2010, 8, 1122-1152, doi:10.3390/md8041122.

14. Montgomery, L.; Seys, J.; Mees, J. To pee, or not to pee: a review on envenomation and treatment in European jellyfish species. Marine Drugs 2016, 14, 127. doi: 10.3390/md14070127

15. Friedel, N.; Scolnik, D.; Adir, D.; Glatstein, M. Severe anaphylactic reaction to Mediterranean jellyfish (Ropilhema nomadica) envenomation: case report. Toxicology Reports 2016, 3, 427-429, doi:10.1016/j.toxrep.2016.03.006.

16. Bordehore, C.; Nogué, S.; Gili, J.M.; Acevedo, M.J.; Fuentes, V.L. Carybdea marsupialis (Cubozoa) in the Mediterranean Sea: the first case of a sting causing cutaneous and systemic manifestations. Journal of Travel Medicine 2015, 22, 61-63, doi:10.1111/jtm.12153.

17. Tezcan, Ö.D.; Gözer, Ö. Severe toxic skin reaction caused by a common anemone and identification of the culprit organism. Journal of Travel Medicine 2015, 22, 269-271, doi:10.1111/jtm.12223.

18. De Donno, A.; Idolo, A.; Bagordo, F.; Grassi, T.; Leomanni, A.; Serio, F.; Guido, M.; Canitano, M.; Zampardi, S.; Boero, F.; et al. Impact of stinging jellyfish proliferations along south Italian coasts: human health hazards, treatment and social costs. International Journal of Environmental Research and Public Health 2014, 11, 2488-2503, doi:10.3390/ijerph110302488.

19. Marambio, M.; Canepa, A.; Lòpez, L.; Gauci, A.A.; Gueroun, S.K.M.; Zampardi, S.; Boero, F.; Yahia, O.K.-D.; Yahia, M.N.D.; Fuentes, V.; et al. Unfolding jellyfish bloom dynamics along the Mediterranean basin by transnational citizen science initiatives. Diversity 2021, 13, 274, doi:10.3390/d13060274.

20. Abody, Z.; Klein-Kremer, A. Anemonia sulcata sting. Harefuah 2006, 145, 736-737, 782.

21. Tezcan, Ö.D.; Sarp, S. An unusual marine envenomation following a rope contact: a report on nine cases of dermatitis caused by Pennaria disticha. Toxicon 2013, 61, 125-128, doi:10.1016/j.toxicon.2012.10.019.

22. Wiedenmann, J.; Leutenegger, A.; Gundel, S.; Schmitt, F.; D'Angelo, C.; Funke, W. Long-term monitoring of space competition among fluorescent and nonfluorescent sea anemones in the Mediterranean Sea. Journal of the Marine Biological Association of the United Kingdom 2007, 87, 851-852, doi:10.1017/S0025315407057050. 
23. Chintiroglou, C.; Koukouras, A. A Population of the Sea Anemone Anemonia viridis (Főrskal, 1775) and its associated flora and fauna, in the North Aegean Sea. Internationale Revue der gesamten Hydrobiologie und Hydrographie 1992, 77, 483-495, doi:10.1002/iroh.19920770311.

24. Mallien, C.; Porro, B.; Zamoum, T.; Olivier, C.; Wiedenmann, J.; Furla, P.; Forcioli, D. Conspicuous morphological differentiation without speciation in Anemonia viridis (Cnidaria, Actiniaria). Systematics and Biodiversity 2018, 16, 271-286, doi:10.1080/14772000.2017.1383948.

25. Porro, B.; Mallien, C.; Hume, B.C.C.; Pey, A.; Aubin, E.; Christen, R.; Voolstra, C.R.; Furla, P.; Forcioli, D. The many faced symbiotic snakelocks anemone (Anemonia viridis, Anthozoa): host and symbiont genetic differentiation among colour morphs. Heredity 2020, 124, 351-366, doi:10.1038/s41437-019-0266-3.

26. Arossa, S.; Cerrano, C.; Barucca, M.; Carducci, F.; Puce, S.; Di Camillo, C.G. An integrative study of Anemonia viridis (Forsskål, 1775) and Aiptasia couchii (Cocks, 1851) (Cnidaria: Anthozoa) from the North Adriatic Sea. Zoomorphology 2021, 140, 421-435, doi:10.1007/S00435-021-00539-Z.

27. Pais, J.J.; Agudo, C.P.; García, L.D.; Moldes, R.M.; Matín, G.M. Picadura de anémona en pene. Actas Urologías Esp. 2008, 32, 864.

28. Haddad Junior, V. Environmental dermatology: skin manifestations of injuries caused by invertebrate aquatic animals. Anais Brasileiros de Dermatologia 2013, 88, 496-506, doi:10.1590/abd1806-4841.20132587.

29. Ballesteros, A.; Marambio, M.; Fuentes, V.; Narda, M.; Santín, A.; Gili, J.M. Differing effects of vinegar on Pelagia noctiluca (Cnidaria: Scyphozoa) and Carybdea marsupialis (Cnidaria: Cubozoa) stings-Implications for First Aid Protocols. Toxins 2021, 13, doi:10.3390/toxins13080509.

30. Anderson, E.R.; Glasier, A. Emergency contraception. Infertility and Reproductive Medicine Clinics of North America 2000, 11, 705-713.

31. Wilcox, C.; Headlam, J.; Doyle, T.; Yanagihara, A. Assessing the efficacy of first-aid measures in Physalia sp. envenomation, using solution- and blood agarose-based models. Toxins 2017, 9, 149, doi:10.3390/toxins9050149.

32. Doyle, T.; Headlam, J.; Wilcox, C.; MacLoughlin, E.; Yanagihara, A. Evaluation of Cyanea capillata sting management protocols using ex vivo and in vitro envenomation models. Toxins 2017, 9, 215, doi:10.3390/toxins9070215.

33. Pyo, M.J.; Lee, H.; Bae, S.K.; Heo, Y.; Choudhary, I.; Yoon, W.D.; Kang, C.; Kim, E. Modulation of jellyfish nematocyst discharges and management of human skin stings in Nemopilema nomurai and Carybdea mora. Toxicon 2016, 109, 26-32, doi:10.1016/j.toxicon.2015.10.019.

34. Yanagihara, A.; Wilcox, C.; King, R.; Hurwitz, K.; Castelfranco, A. experimental assays to assess the efficacy of vinegar and other topical first-aid approaches on cubozoan (Alatina alata) tentacle firing and venom toxicity. Toxins 2016, 8, 19, doi:10.3390/toxins8010019.

35. Birsa, L.M.; Verity, P.G.; Lee, R.F. Evaluation of the effects of various chemicals on discharge of and pain caused by jellyfish nematocysts. Comparative Biochemistry and Physiology - C Toxicology and Pharmacology 2010, 151, 426430, doi:10.1016/j.cbpc.2010.01.007.

36. Rifkin, J.F.; Fenner, P.J.; Williamson, J.A.H. First Aid Treatment of the sting from the hydroid Lytocarpus philippinus: the structure of, and in vitro discharge experiments with its nematocysts. Journal of Wilderness Medicine 1993, 4, 252-260, doi:10.1580/0953-9859-4.3.252.

37. Zaragozano, J.F. Mordeduras, picaduras y otras lesiones producidas por animales que viven en el agua. Boletín de la Sociedad de Pediatría de Aragón, La Rioja y Soria 2016, 46, 10-18.

38. Nogué, S.; Martín, C.; Gili, J.M.; Atienza, D.; Fuentes, V.; Vernet, D. Animales marinos. In Urgencias por contacto, picadura o mordedura de animales venenosos, Nogué, S.; Martín, C.; Gili, J.M.; Atienza, D.; Fuentes, V.; Vernet, D. Eds.; Área Científica Menarini y Hostital Clínic de Barcelona: Barcelona, 2008; pp. 38-59.

39. Field-Cortazares, J.; Calderón-Campos, R.; Luis, J.; Moreno, S.-Y. Picadura por anémona. Boletín Clínico Hospital Infantil del Estado de Sonora 2011, 28, 34-37.

40. Veraldi, S.; Carrera, C. Delayed cutaneous reaction to jellyfish. International Journal of Dermatology $2000,39,28-29$.

41. Tsai, H.S.; Niu, K.Y. acute skin manifestation of sea anemone envenomation. Journal of Emergency Medicine 2021, 60, 536-537, doi:10.1016/j.jemermed.2020.11.025.

42. Loredana Asztalos, M.; Rubin, A.I.; Elenitsas, R.; Groft Macfarlane, C.; Castelo-Soccio, L. Recurrent dermatitis and dermal hypersensitivity following a jellyfish sting: a case report and review of literature. Pediatric Dermatology 2014, 31, 217-219, doi:10.1111/pde.12289. 
43. Guest, H.; Lotze, H.K.; Wallace, D. Youth and the sea: ocean literacy in Nova Scotia, Canada. Marine Policy 2015, 58, 98-107, doi:10.1016/j.marpol.2015.04.007.

44. Fortner, R.W.; Mayer, V.J. Repeated measures of students' marine and great lakes awareness. Journal of Environmental Education 1991, 23, 30-35, doi:10.1080/00958964.1991.9943067.

45. Brody, M.J. An assessment of 4th-, 8th-, and 11th-grade students' environmental science knowledge related to oregon's marine resources. Journal of Environmental Education 1996, 27, 21-27, doi:10.1080/00958964.1996.9941463.

46. Salazar, J.; Dominguez-Carrió, C.; Gili, J.M.; Ambroso, S.; Grinyó, J.; Vendrell-Simón, B. Building a new ocean literacy approach based on a simulated dive in a submarine: a multisensory workshop to bring the deep sea closer to people. Frontiers in Marine Science 2019, 6, 576, doi:10.3389/fmars.2019.00576.

47. Observadores Del Mar Available online: https://www.observadoresdelmar.es/ (accessed on 12 November 2021).

48. Ballesteros, A.; Marambio, M.; Fuentes, V.; Gili, J.-M. The use of a citizen science tool (IMEDJELLY App) to deliver First Aid Protocols for Mediterranean jellyfish stings. In Proceedings of the VII International Symposium on Marine Sciences; 2020.

59. Marambio, M.; López, L.; Kéfi-Daly Yahia, O.; Daly Yahia, N.; Deidun, A.; Piraino, S.; Nunes, P.A.L.D.; Fuentes, V. The Medjelly App: a preventive and mitigation tool against jellyfish blooms involving a citizen science network. In Proceedings of the V Jellyfish Blooms Symposium; 2016.

50. Kingsford, M.J.; Becken, S.; Bordehore, C.; Fuentes, V.L.; Pitt, K.A.; Yangihara, A.A. Empowering stakeholders to manage stinging jellyfish: a perspective. Coastal Management 2018, 46, 1-18, doi:10.1080/08920753.2018.1405326.

51. Uri, S.; Marina, G.; Liubov, G. Severe delayed cutaneous reaction due to Mediterranean jellyfish (Rhopilema nomadica) Envenomation. Contact dermatitis 2005, 52, 282-283, doi:10.1111/j.0105-1873.2005.00582.x.

52. Burnett, J.W. Medical aspects of jellyfish envenomation: pathogenesis, case reporting and therapy. Hidrobiologia 2001, 451, 1-9,

53. DeClerck, M.P.; Bailey, Y.; Craig, D.; Lin, M.; Auerbach, L.J.; Linney, O.; Morrison, D.E.; Patry, W.; Auerbach, P.S. Efficacy of topical treatments for Chrysaora chinensis species: a human model in comparison with an in vitro model. Wilderness \& Environmental Medicine 2016, 27, 25-38, doi: 10.1016/j.wem.2015.10.008

54. Morabito, R.; Marino, A.; Dossena, S.; la Spada, G.Nnematocyst discharge in Pelagia noctiluca (Cnidaria, Scyphozoa) oral arms can be affected by lidocaine, ethanol, ammonia and acetic acid. Toxicon 2014, 83, 52-58, doi:10.1016/j.toxicon.2014.03.002.

55. Nogué, S.; Gili, J.M. Toxicidad por picadura de medusas. Jano 2006, 1816, 45-46.

56. Wilcox, C.; Yanagihara, A. heated debates: hot-water immersion or ice packs as first aid for cnidarian envenomations? Toxins 2016, 8, 97, doi:10.3390/toxins8040097.

57. Exton, D.R.; Fenner, P.J.; Williamson, J.A. Cold packs: effective topical analgesia in the treatment of painful stings by Physalia and other jellyfish. Medical Journal of Australia 1989, 151, 625-626, doi:10.5694/j.13265377.1989.tb139632.x. 